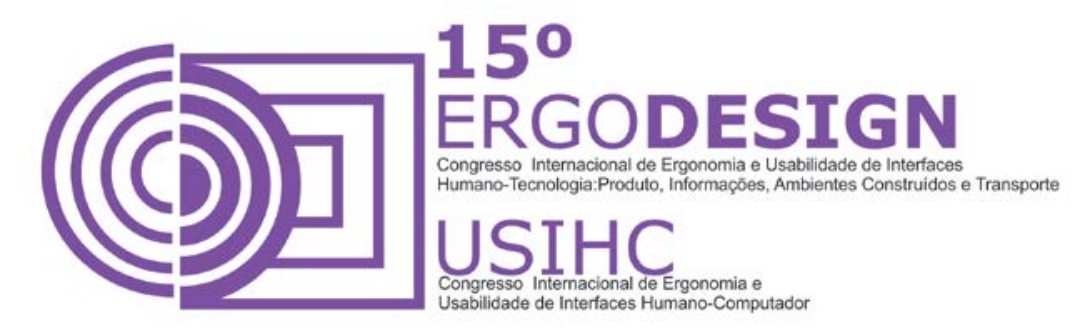

\title{
APLICAÇÕES DE DESIGN DE INTERFACE E PROCESSO COGNITIVO NA ELABORAÇÃO DE PRODUTOS VIRTUAIS INTERATIVO
}

\section{APPLICATIONS OF INTERFACE DESIGN AND COGNITIVE PROCESS IN THE DEVELOPMENT OF INTERACTIVE VIRTUAL PRODUCTS}

\author{
LIMA, Michell Angelo Santos (1); \\ SANTOS, Pedro Henrique Batista Dos (2) \\ (1) Universidade Federal de Sergipe, Mestre em Administração \\ E-mail: michell.aju@gmail.com \\ (2) Universidade Federal de Sergipe, Graduando em Design \\ E-mail: ph.sport@gmail.com
}

\begin{abstract}
RESUMO
A elaboração de interfaces para usuários que possuem dificuldades motoras exige que seja facilitada o acesso às informações ao considerarmos suas limitações. Portanto, esta pesquisa elaborar uma proposta de interface para um produto virtual interativo voltado para deficientes motores. Para tanto, serão utilizadas técnicas de card sorting, wire frame e prototype paper. Espera-se que esta pesquisa contribua para ampliação do campo teórico e servindo assim, de instrução normativa e/ou comparação de resultados para outras pesquisa.

Palavras-chave: Design de interface, Produtos Virtuais Interativos, Dificuldades motoras.
\end{abstract}

\begin{abstract}
The development of interfaces for users who have motor difficulties requires measures to facilitate access to information to consider its limitations. Therefore, this research develop an interface proposal for an interactive virtual product designed for disabled guests. For this, we used techniques of card sorting, wire frame and paper prototype. It is hoped that this research will contribute to expanding the theoretical field and thus serving of normative instruction and / or compare the results to other research.
\end{abstract}

Keywords: Interface design, Interactive Virtual Products, Motor difficulties. 


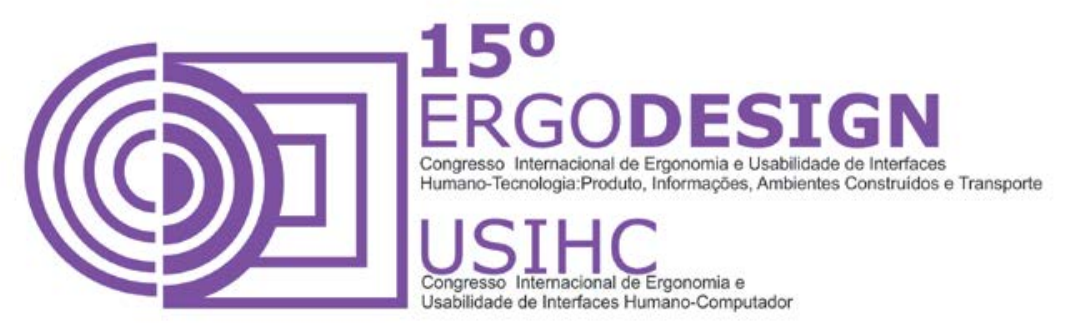

\section{INTRODUÇÃO}

Ao considerar os princípios das teorias que embasam o design de interface e os aspectos do processo cognitivo dos usuários percebe-se a importância de ser construída uma arquitetura da informação adequada para o projeto, a qual objetiva facilitar o acesso às informações em uma determinada interface. Para tanto, utiliza-se quatro diretrizes principais: a organização do conteúdo, a navegação, a boa identificação de elementos que representam informações (signos), e a possibilidade de não reativação de memória do usuário. Além disso, são realizados testes de usabilidade com o intuito de avaliar o projeto antes que ele seja executado e assim reduzindo retrabalhos.

Desse modo, esta pesquisa visa, baseados nos princípios do design de interface, elaborar uma proposta de interface para um produto virtual interativo para deficientes motores. As ações propostas nesta pesquisa tem o empenho de destacar a importância e de desenvolver uma sinergia entre a compreensão de conteúdo, contexto e usuário nos projetos de design de interfaces. Para alcançar este objetivo, é necessário: identificar como os usuários organizam as informações; projetar como serão organizadas as informações e avaliar a usabilidade desta organização; proceder a pesquisa tipográfica e o estudo das cores que comporão o projeto; elaborar uma proposta de uma interface de um produto virtual interativo para deficientes motores.

\section{REFERENCIAL BIBLIOGRÁFICO}

As deficiências motoras são causadas por diversos tipos de situações, como causas genéticas e problemas durante a gestação ou parto.No tocante aos pacientes que serão beneficiados, estas dificuldades motoras que estes apresentam interferem diretamente em atividades diárias que eles desempenham, tais como ir ao banheiro, vestir-se ou alimentar-se de forma independente. Estas limitações podem interferir na autoestima do paciente, assim como na sua socialização e na inserção em ambientes escolares e profissionais.

Considerando este cenário, vários estudos multidisciplinares estão sendo desenvolvidos buscando elaborar ambientes virtuais que levem em consideração as dificuldades destes pacientes. Este tipo de projeto exige conhecimento e empenho de equipes multidisciplinares, nas quais conhecimentos em tecnologia e saúde são fundamentais. No entanto, observa-se nos trabalhos que referenciam este projeto que não utilizam conhecimentos da área de Design, mais especificamente de conceitos de design de interação, que utilizam fundamentos de usabilidade e ergonomia para indicar melhores práticas na elaboração de novos produtos buscando uma melhor experiência do usuário.

Para tanto, este trabalho norteou-se pela heurística de usabilidade de Nielsen, o qual listou dez qualidades base para qualquer interface. São 10 itens para a avaliação da usabilidade com intuito de evitar erros comuns e que podem prejudicar e muito a experiência do usuário (CYBYS et al., 2007). 


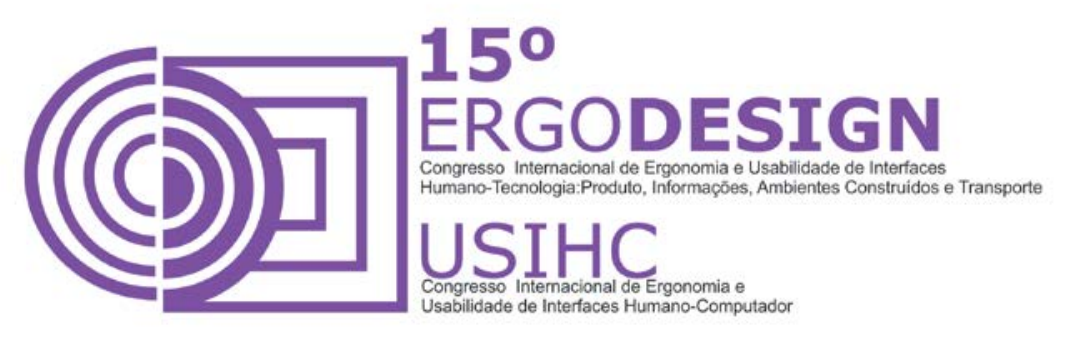

\section{PROCEDIMENTOS METODOLÓGICOS}

Para a realização do projeto será construída uma arquitetura da informação adequada ao projeto, a qual objetiva facilitar o acesso às informações em uma determinada interface. Para tanto, será realizada a técnica que macro arquitetura, que permitirá dissecar e analisar a organização e as informações pertinentes ao projeto. Essas informações serão elencadas e direcionadas para etapa de projetação do jogo, na qual será primeiramente estudado o público idealizado através da técnica de personas e o contexto que será levantado através de técnica de cenário futuro, possibilitando a compreensão o contexto e os usuários nos quais as decisões sobre o projeto estarão centralizadas.

Desse modo, serão utilizadas as seguintes técnicas para conhecer os usuários: Aplicação da técnica de card sorting, que consiste em buscar, por meio de um jogo de cartas, identificar como os usuários organizam as informações do jogo, de modo a compreender o modelo mental do usuário diante das informações existentes; Técnica de Wireframe (HAGBI, 2010), que faz parte da etapa de prototipação do jogo, na qual serão projetados os espaços de uso das informações de maneira simples e posteriormente detalhada em um modelo mais elaborado em papel; Técnica de Prototype Paper (LANDAY; MYERS, 1995; 2001), que desenvolve em papel todos os tipos de interação existentes no jogo, analisando a capacidade de uso desse ambiente no que concerne à interatividade do produto.

Com estes dados, será procedida a pesquisa tipográfica e o estudos das cores para a proposta para então produzir a interface gráfica do projeto. Com a proposta elaborada, é realizada sua homologação através de simulações e testes com os usuários (pacientes com dificuldades motoras e terapeutas) de modo a identificar e proceder possíveis correções.

\section{RESULTADOS ESPERADOS}

Como resultado de pesquisa, pretende-se ampliar o campo teórico e profissional, servindo assim, de instrução normativa e/ou comparação de resultados para outras pesquisas, obedecendo as características sistemáticas de validação internas/externas necessárias, que uma pesquisa cientifica exige, promovendo a possibilidade de que a mesma metodologia possa ser reaplicada em outras possíveis pesquisas ou simplesmente discutida.

\section{REFERÊNCIAS BIBLIOGRÁFICAS}

CYBIS, Walter de Abreu; BETIOL, Adriana Holtz; FAUST, Richard. Ergonomia e usabilidade: conhecimentos, métodos e aplicações. Novatec Editora, 2007.

HAGBI, Nate et al. In-place sketching for content authoring in augmented reality games. In: Virtual Reality Conference (VR), 2010 IEEE. IEEE, 2010. p. 91-94.

LANDAY, James A.; MYERS, Brad A. Interactive sketching for the early stages of user interface design. In: Proceedings of the SIGCHI conference on Human factors in computing systems. ACM Press/Addison-Wesley Publishing Co., 1995. p. 43-50. 


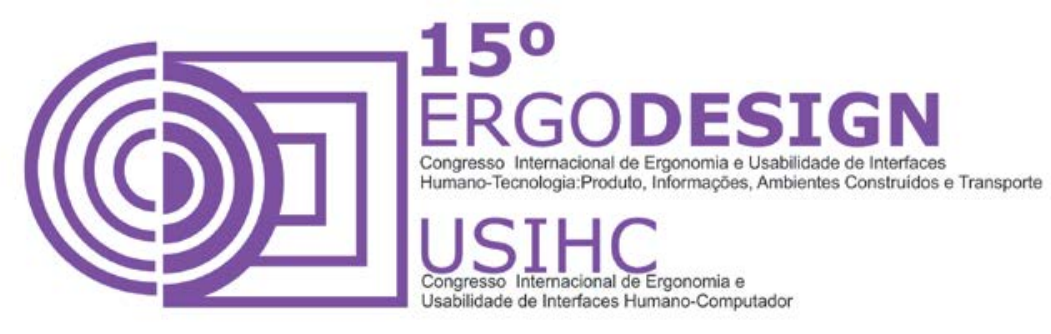

LANDAY, James A.; MYERS, Brad A. Sketching interfaces: Toward more human interface design. Computer, v. 34, n. 3, p. 56-64, 2001. 